\title{
Políticas de comunicación de los gobiernos catalanes en los años del procés independentista (2012-2020) ${ }^{1}$
}

\section{Communication Policies of Successive Catalan Governments in the Years of the Pro- independence Process (2012-2020)}

\author{
Isabel Fernández Alonso ${ }^{2}$ \\ Universidad Autónoma de Barcelona (España)
}

ORCID: https://orcid.org/0000-0003-4544-7589

Recibido: 05-04-2021

Aceptado: 24-04-2021

\section{Resumen}

Este artículo sistematiza y analiza las principales estrategias de los gobiernos nacionalistas catalanes en materia de políticas de medios en los años del denominado procés independentista, que arranca con la gran manifestación separatista de septiembre de 2012 y se eclipsa con el estallido de la pandemia del Covid-19.

Apunta cuatro líneas principales de actuación: la instrumentalización de los medios públicos regionales, la adjudicación de licencias de emisión a empresas privadas afines, el clientelismo en la transferencia de fondos públicos a esas

\footnotetext{
${ }^{1}$ Este artículo se enmarca en el proyecto "Impacto de la financiación pública en la economía de las empresas mediáticas privadas. Subvenciones y publicidad institucional. Análisis del caso español (2008-2020). Ministerio de Ciencia, Innovación y Universidades. Plan Nacional de I+D+i, Programa Estatal de Generación del Conocimiento y Fortalecimiento Científico y Tecnológico (2019-2021). Ref. PGC2018-093887-B-I00.

${ }^{2}$ (mariaisabel.fernandez@uab.es). Directora del Grupo de Investigación en Estructura y Políticas de Comunicación Daniel Jones de la Universidad Autónoma de Barcelona (https://grupodanieljones. org/). Entre las publicaciones, cabe mencionar: Fernández Alonso, Isabel y Santana, Fernanda (2000): Estado y medios de comunicación en la España democrática. Madrid: Alianza Universidad. Fernández Alonso, Isabel (2016): "Independent Audiovisual Regulators in Spain: A Unique case in Europe", en International Journal of Communication, vol. 10, pp. 359-376. Fernández Alonso, Isabel (2017) (ed.): Austeridad y clientelismo. Política audiovisual en España en el contexto mediterráneo y de la crisis financiera. Barcelona: Gedisa.
} 
mismas empresas privadas y los mecanismos de presión y seducción a periodistas extranjeros.

Todo ello entendido como una aceleración del proyecto de articulación de un sistema mediático propio, iniciado en los años ochenta, con el fin de avanzar en el proceso de nacionalización de Cataluña.

Palabras-clave: política de medios, Cataluña, nacionalismo, clientelismo

\begin{abstract}
This article systematises and analyses the successive Catalan nationalist governments' main media policy strategies in the years of the so-called 'proindependence process', which began with a massive separatist demonstration in September 2012 and has since been eclipsed by the COVID-19 pandemic.

It highlights four main lines of action: the instrumentalisation of regional public media; the granting of broadcast licences to private firms sympathetic to the cause; clientelism in the transfer of public funds to those private firms; and the mechanisms for pressurising and seducing foreign journalists.

All of the above can be understood as an acceleration of the project to articulate an own media system, which had begun in the 1980s, for the purpose of furthering Catalonia's nation-building process.
\end{abstract}

Keywords: media policy, Catalonia, nationalism, clientelism.

\title{
1.Políticas de comunicación, espai català de comunicació y construcción nacional
}

A principios de los años ochenta, inspirada en el debate desarrollado en la UNESCO entre los partidarios del free flow of information y los defensores de un Nuevo Orden Mundial de la Información y la Comunicación (NOMIC), emerge con fuerza en el ámbito académico catalán (Gifreu, 1983) la idea de políticas (nacionales) de comunicación, entendidas como la herramienta clave para la articulación de un sistema mediático propio, diferenciado del español, y abarcador de todos los territorios de habla catalana (Gifreu y Corominas, $1991)^{3}$.

\footnotetext{
3 Las políticas nacionales de comunicación, tal como las plantean en el contexto del referido debate los Países No Alineados (impulsores del NOMIC), son un instrumento esencial para el logro de tres grandes objetivos: el desarrollo social y económico de los países más pobres; el impulso de la democracia participativa; y la definición y/o reforzamiento de las identidades culturales, algo especialmente relevante en el caso de aquellos territorios que habían vivido recientemente procesos de descolonización (Gifreu, 1986: 104-113).
} 
Ese sistema mediático propio, bautizado como espai català de comunicació, con el tiempo, como resultado de las políticas del nacionalismo más conservador (1980-2003) y de las lógicas resistencias de las otras regiones catalanohablantes, ha quedado circunscrito al territorio de la comunidad autónoma de Cataluña.

En todo caso, los diferentes analistas, empezando por los académicos que impulsaron la idea, coinciden en el rol central de esos medios propios -de ese espai català de comunicació- para la difusión del discurso que ha sustentado el denominado proceso de construcción nacional de Cataluña (Guimerà i Orts, 2014), que alcanzaría un evidente punto de inflexión con la gran manifestación independentista del 11 de septiembre de 2012.

En síntesis, las políticas de comunicación del gobierno de la emergente Comunidad Autónoma de Cataluña debían orientarse a la articulación de un ecosistema mediático diferenciado del español que, a su vez, contribuyese al fortalecimiento del movimiento nacionalista catalán.

La mejor evidencia de que esta idea se puso de inmediato en práctica la constituye un documento, el conocido como Programa 2000, que Jordi Pujol Presidente de la Generalitat de Cataluña entre 1980 y 2003- entregó a su equipo de gobierno para debatirlo en una reunión mantenida el 3 de septiembre de 1990. Se trataba de un plan de nacionalización que pretendía incidir en diversos ámbitos de la sociedad catalana, si bien tenía como objetivos prioritarios "la escuela (...); los medios de comunicación de masas, especialmente los medios públicos audiovisuales; y la socio-cultura (...)".

En lo que respecta a los medios de comunicación, el denominado Programa 2000 se proponía, por ejemplo, "conseguir que los medios de comunicación públicos dependientes de la Generalitat sean transmisores eficaces del modelo nacional catalán"; "incidir en la formación inicial y permanente de los periodistas y de los técnicos en comunicación para garantizar una preparación con conciencia nacional catalana"; o "introducir a gente nacionalistas con una elevada profesionalidad y una gran cualificación técnica en todos los lugares clave de los medios". El plan iba acompañado de un listado titulado "Pensamiento, agentes actuantes", entre los que figura Josep Gifreu, entonces profesor de la Universidad Autónoma de Barcelona y principal teórico del espai català de comunicación ${ }^{4}$.

No obstante, los académicos catalanes se centran exclusivamente en el tercero de estos objetivos a la hora de trasladar, de un modo claramente forzado, este debate al ámbito catalán. Sostengo que el traslado es forzado porque, en aquel momento, la Constitución de 1978, avalada en referéndum por más del $90 \%$ de los catalanes, consagraba ya un modelo de Estado descentralizado en el que las comunidades autónomas pasarían a tener importantes competencias en materia de cultura y medios de comunicación dejando, por tanto, atrás el proceso de uniformización cultural que, sin duda, había implicado la dictadura franquista.

${ }^{4}$ El Programa 2000 se ha publicado en varios números, de septiembre y octubre de 2019, del semanario El Triangle. El ejemplar dedicado a los medios es el del 18 de septiembre (p. 7) y el que 
Así las cosas, Guimerà i Orts y Fernández Viso (2014) han sintetizado las principales actuaciones en materia de políticas de comunicación desarrolladas por los sucesivos ejecutivos catalanes entre 1980 y 2010, con el objetivo de articular esa esfera mediática propia -en lengua catalana-, en frecuente tensión competencial con el Gobierno de España ${ }^{5}$. Entre esas políticas subrayan el impulso de una potente corporación audiovisual pública -la Corporación Catalana de Medios Audiovisuales (CCMA)-, la adjudicación de licencias -de radio y televisión terrestre de cobertura autonómica y local- y el otorgamiento de abundantes subvenciones al sector privado (prensa, radio y televisión). Los autores apuntan que todo ello explica la creación de grupos multimedia autóctonos competitivos.

De este modo, en 2012, cuando el movimiento nacionalista deviene abiertamente independentista, generando una tensión territorial sin precedentes en la historia de la democracia española, Cataluña cuenta con una oferta de medios públicos sin parangón en otras comunidades autónomas españolas y con un potente sistema de medios privados -de alcance autonómico, comarcal y local- muy dependiente de las subvenciones y otras formas de financiación pública, en particular de los ingresos derivados de las campañas de publicidad institucional (Civil et al., 2013).

En definitiva, un sistema mediático que responde a las características propias de los denominados sistemas pluralistas polarizados -los sistemas mediterráneos-, con algunas especialmente marcadas como es el caso del fuerte intervencionismo gubernamental en los medios y también en el ejercicio del periodismo (Hallin y Mancini, 2008). Veremos abundantes ejemplos en las páginas que siguen.

\section{Giro independentista de $\mathrm{CiU}$ y deriva unilateral del separatismo}

Este artículo se centra en las políticas desplegadas por la Generalitat de Cataluña en materia de medios -políticas de comunicación ${ }^{6}$ - entre 2012 y 2020, los años del denominado procés independentista cuya centralidad en el

recoge el listado de agentes actuantes, el del 2 de octubre (p. 6). En 1990 la prensa había recogido una versión reducida.

5 La Constitución Española de 1978 establece que el Estado tiene competencia exclusiva sobre las "normas básicas del régimen de prensa, radio y televisión y, en general, de todos los medios de comunicación social, sin perjuicio de las facultades que en su desarrollo y ejecución correspondan a las comunidades autónomas" (artículo 149.1.27). El reparto concreto de competencias en materia de medios se ha ido perfilando con el paso de los años, observándose una tendencia creciente a la transferencia de competencias a las comunidades que, en general, gozan de un amplio margen para impulsar sus propios medios audiovisuales, públicos y privados, en función, eso sí, de las limitaciones de espectro radioeléctrico cuya planificación depende exclusivamente del Gobierno español.

${ }^{6}$ En la academia y en la praxis política catalana se habla sistemáticamente de políticas de comunicación para referirse a las políticas de medios.

Araucaria. Revista Iberoamericana de Filosofía, Política, Humanidades y Relaciones Internacionales, año $23, \mathrm{n}^{\circ} 47$. Segundo cuatrimestre de 2021. Pp. 294-314. ISSN 1575-6823 e-ISSN 2340-2199 https://dx.doi.org/10.12795/araucaria.2021.i47.14 
debate público ha quedado en buena medida eclipsada por la gran pandemia del Covid-19.

En estos más de ocho años en que el Gobierno de la Generalitat ha estado siempre en manos de fuerzas políticas independentistas, el sistema político catalán ha vivido una transformación extraordinaria de la que son buena prueba la desintegración de Convergència i Unió (CiU) -una coalición nacionalista liberal-democristiana que había gobernado ininterrumpidamente entre 1980 y 2003 y había recuperado el poder en 2010, sin haberse manifestado nunca como independentista-; el auge progresivo de Ciudadanos -un partido liberal constitucionalista, fundado en 2006, que ha logrado arrastrar a buena parte del electorado socialdemócrata no nacionalista- y de Esquerra Republicana de Catalunya (ERC) - una fuerza radicalmente independentista que tiene su origen en la Segunda República-; y el papel bisagra de la Candidatura d'Unitat Popular (CUP), un partido ultranacionalista y antisistema que, sin entrar a formar parte de los sucesivos gobiernos de este periodo, ha sido esencial para que el separatismo haya podido conservar la mayoría absoluta en el Parlamento autonómico ${ }^{7}$.

Coincidiendo con el evidente fortalecimiento del movimiento independentista, que se plasma en la gran manifestación del 11 de septiembre de 2012, el entonces presidente de la Generalitat y líder de CiU, Artur Mas, que gobernaba desde 2010 con el apoyo del Partido Popular de Cataluña (PPC), da un giro separatista ${ }^{8}$ y convoca elecciones autonómicas para el 25 de noviembre de este mismo año, confiado en reforzar su mayoría. El argumento que esgrimió, además de la gran movilización del 11 de septiembre y la recurrente sentencia del Tribunal Constitucional -que había anulado en 2010 algunos puntos del nuevo Estatuto de Autonomía de Cataluña ${ }^{9}$, fue la negativa del Gobierno español, en manos del PP desde finales de 2011, a aceptar un "pacto fiscal", inasumible en un contexto de fortísima crisis económica.

Sin embargo, como apunta Joaquim Coll (2018: 24-27), parece más atinado pensar que Mas actuó movido por el enorme riesgo que para su futuro político podría implicar gobernar dependiendo de un Partido Popular que, además, no le necesitaba en Madrid, donde contaba con mayoría absoluta ${ }^{10}$. El

\footnotetext{
${ }^{7}$ La CUP, hasta entonces limitada al entorno municipal, entra en la cámara autonómica en 2012.

${ }^{8}$ A finales de 2011 había rechazado en la televisión pública autonómica "un planteamiento cortoplacista que pase por dividir a la sociedad catalana en dos mitades" (Coll, 2018: 24).

${ }^{9}$ Este argumento, utilizado sistemáticamente por el separatismo, no encaja con el hecho de que, con posterioridad a la sentencia, CiU y el PP -que había recogido cuatro millones de firmas para acompañar una proposición de ley que pedía un referendo en toda España sobre el nuevo Estatuto y que luego lo había recurrido ante el más alto tribunal español- se dieran apoyo mutuo en los parlamentos catalán y nacional.

${ }^{10}$ El último Gobierno de Jordi Pujol (2000-2003), con el apoyo del Partido Popular de Cataluña, había relegado a CiU a la oposición durante siete años en los que se habían articulado gobiernos de coalición -los denominados tripartitos- entre socialistas, republicanos independentistas y ecologistas (2003-2010).
} 
viraje independentista le permitía, a la vez, desviar la atención de los tremendos recortes que estaba aplicando su Gobierno y de los graves casos de corrupción que rodeaban a su partido. Todo ello sin olvidar que nada de esto habría sido posible sin el plan de nacionalización que se plasmó en el referido Programa 2000 y que había ido calando como una lluvia fina en la sociedad catalana desde hacía décadas.

Sin embargo, los resultados de las elecciones de 2012 no fueron los esperados. CiU pierde 12 escaños y necesitará del apoyo parlamentario de ERC para conformar el nuevo gobierno. En un marco de creciente tensión separatista, en septiembre de 2015 se celebran otras elecciones (plebiscitarias) en las que las dos principales fuerzas secesionistas - Convergència Democràtica de Catalunya $(\mathrm{CDC})^{11}$ y ERC- concurren, junto a personalidades de las principales organizaciones sociales independentistas, bajo la marca electoral Junts pel Sí. Esta coalición gobernará entre enero de 2016 y octubre de 2017, gracias al apoyo parlamentario de la CUP, que exige que Mas no repita como presidente, siendo sustituido por Carles Puigdemont al frente de la Generalitat. El independentismo cuenta con mayoría absoluta en escaños, pero pierde el denominado plebiscito, al obtener solo el $47 \%$ de los votos. La deriva separatista se acelera para desembocar en el referendo ilegal del 1 de octubre de 2017 y en la declaración unilateral de independencia del 27 del mismo mes. Todo ello tras numerosas advertencias del Tribunal Constitucional por la vulneración sistemática de la legalidad, especialmente grave con la aprobación, en las sesiones parlamentarias del 6 y 7 de septiembre, de las denominadas "leyes de desconexión" que suponían, de facto, un intento de derogación de los órdenes estatutario y constitucional en Cataluña.

Tras la declaración unilateral de independencia, el Senado español aprueba el cese del Gobierno catalán y la intervención de la Generalitat. Puigdemont huye a Bélgica. De inmediato, el presidente del Gobierno español, Mariano Rajoy, convoca elecciones autonómicas para el 21 de diciembre de 2017. Aunque en estos comicios - por tercera vez en la Cataluña autonómica- un partido constitucionalista, Ciudadanos, resulta la fuerza más votada, nuevamente los partidos independentistas obtienen mayoría absoluta de escaños, manteniéndose en el $47 \%$ de los sufragios. En esta ocasión no se había configurado una gran coalición electoral. La fuerza separatista más votada es Junts per Catalunya, el partido del ex presidente Puigdemont, que se presenta como "presidente legítimo en el exilio", seguida de ERC, con su líder y ex vicepresidente de la Generalitat, Oriol Junqueras, en prisión provisional. Nuevamente requieren del apoyo de la CUP para formar gobierno. Tras complejas negociaciones, Joaquim Torra, que había sido presidente de Òmnium Cultural - una de las grandes

${ }^{11}$ Unió Democràtica de Catalunya (UDC), el ala democristiana de CiU, abandona la coalición, como consecuencia de su deriva secesionista, en junio de 2015. 
entidades sociales independentistas- se convierte en el nuevo Presidente de la Generalitat en mayo de 2018. Torra será inhabilitado por los tribunales -el Tribunal Supremo ratifica la sentencia del Tribunal Superior de Justicia de Cataluña- en septiembre de 2020 por negarse a obedecer una resolución de la Junta Electoral Central que le obligaba a retirar una pancarta en apoyo a los presos del procés del balcón del Palau de la Generalitat. Este hecho desembocará en unas nuevas elecciones autonómicas, celebradas el 14 de febrero de 2021, en las que el separatismo supera por primera vez el 52\% de los votos, resultando vencedor el Partido de los Socialistas de Cataluña (PSC), a la vez que se advierte un descalabro electoral de Ciudadanos, coincidiendo con un llamativo descenso de la participación y una importante crisis de este partido a nivel nacional.

\section{Principales actuaciones de la Generalitat en materia de medios}

Así las cosas, CiU -y sus herederos, el Partido Demócrata de Cataluña (PDeCAT) y Junts per Catalunya- y ERC se reparten durante estos años (2012-2018) la gestión de las políticas de comunicación en Cataluña, lo que conllevará, como explicaremos, algunas tensiones entre ambos.

En las páginas que siguen nos centraremos en sus actuaciones en los tres ámbitos que, como hemos visto, han sido tradicionalmente nucleares en estas políticas: los medios públicos, la adjudicación de licencias de radio y televisión terrestre y la financiación pública del sector mediático privado. Añadiremos un apartado dedicado a las iniciativas de la Generalitat orientadas a los medios extranjeros, claves para que la mirada nacionalista sobre lo que sucedía en Cataluña durante los años del denominado procés pudiese calar en la opinión pública internacional.

\subsection{Instrumentalización de los medios públicos}

El sistema audiovisual público regional español no tiene parangón en Europa. Trece de las diecisiete comunidades autónomas han ido impulsando progresivamente, desde principios de los años ochenta, sus propias corporaciones audiovisuales públicas. De todas ellas, la catalana es la que siempre ha contado con una oferta programática más amplia y también con una financiación más cuantiosa. Prueba de ello es que es que solo Cataluña dispone de dos múltiplex de TDT de cobertura autonómica, destinando uno completo a la televisión pública, mientras que en el resto de comunidades las ofertas pública y privada de televisión regional conviven en el único múltiplex que tienen adjudicado desde 2014. Otro rasgo distintivo del sistema audiovisual público catalán es 
el liderazgo -frente a los canales de cobertura nacional públicos y privados y a los autonómicos privados- de su televisión generalista, TV3, así como la gran influencia de su canal radiofónico generalista, Catalunya Ràdio, segundo en audiencia, solo superado, desde 2009, por RAC1 (Miguel y Casado, 2012; Casado et al., 2017).

A continuación, analizaremos las principales decisiones adoptadas por el Gobierno catalán desde 2012 orientadas, como veremos, al control de la Corporación Catalana de Medios Audiovisuales (CCMA), el ente público que gestiona los medios de comunicación audiovisual de la Generalitat. Abordaremos, asimismo, algunas implicaciones significativas de estas decisiones. Pero antes, cabe apuntar que, cuando se produjo la intervención de la Generalitat, tras la declaración unilateral de independencia, se planteó también la intervención de la CCMA. El Gobierno español pretendía que, hasta que se celebrasen las nuevas elecciones autonómicas, fuese la Junta Electoral Central la encargada de supervisar los medios públicos catalanes (incluida la Agencia Catalana de Noticias ${ }^{12}$ ) y que el control parlamentario de estos medios recayese en la comisión de las Cortes Generales encargada de la aplicación del artículo 155 de la Constitución, en el que se fundamentaba la intervención de la Autonomía. No obstante, esta iniciativa se frenó a raíz de una enmienda del grupo socialista del Senado que, a su vez, recogía las reivindicaciones de numerosas entidades profesionales catalanas y del resto de España, así como de la Federación Europea de Periodistas (Fernández Alonso y Espín, 2019: 46-47).

\subsubsection{Designación de cargos afines al separatismo}

Durante el primer mandato de Artur Mas (2010-2012), en el que, como hemos apuntado, CiU gobierna en minoría con el apoyo del Partido Popular, se aprueba, gracias a la abstención de este y con los únicos votos favorables de los diputados convergentes, la ley 2/2012 de modificación de diversas leyes en materia audiovisual, entre ellas la 11/2007, que regula la organización y funcionamiento de la CCMA.

En concreto, con el argumento de la necesidad de una mejor gestión en el contexto de la crisis financiera, se reforma el sistema de gobierno de

${ }^{12}$ La Agencia Catalana de Noticias (ACN) fue impulsada en 1999 por el Consorcio Local y Comarcal de Comunicación - una entidad pública de carácter asociativo creada un año antes por las diputaciones de Lérida, Tarragona y Gerona, que integraba también a varios ayuntamientos y consejos comarcales- con el objetivo de dotar de contenidos a los medios locales y así fortalecer el denominado espai català de comunicació. Para configurarla jurídicamente se creó la sociedad anónima Intracatalònia que si bien en un primer momento contó con accionistas privados como Planeta o Caixa Catalunya, actualmente está participada únicamente por el sector público: Departamento de la Presidencia de la Generalitat de Cataluña (70\%) y la propia Corporación Catalana de Medios Audiovisuales (30\%). El primer director de la ACN fue Carles Puigdemont. Al igual que sucede con EFE, no existe una ley que regule la organización y control parlamentario de la ACN, tal como exige el artículo 20.3 de la Constitución. 
la corporación audiovisual pública catalana, reduciendo el número de cargos, así como las mayorías necesarias para la designación del consejo de administración y de su presidente, así como para la adopción de acuerdos de especial trascendencia en el seno de este órgano.

De este modo, el consejo de administración -consejo de gobierno en la normativa catalana- queda configurado por 6 miembros, que han de ser elegidos por mayoría de $2 / 3$ del Parlamento catalán en primera votación -hasta entonces la única opción ${ }^{13}$ - o por mayoría absoluta, en segunda. La misma cámara legislativa elegirá, entre ellos y por el mismo procedimiento, al presidente.

No obstante, en marzo de 2012, se produce un acuerdo entre CiU, PP y PSC, que permite la designación de los cargos en primera votación por amplia mayoría. Así, tres consejeros son designados a propuesta de CiU (Duart, Llorach y Pemán), dos a propuesta del PSC (Guitart y Vilar) y uno por iniciativa del PP (Querol). Pero en septiembre del año siguiente, gobernando ya CiU con el apoyo de ERC, Guitart dimite y el consejo funciona durante casi dos años con solo cinco miembros, debido a la negativa de ERC a proponer un sustituto y entrar en el juego de cuotas de partido, ya que su apuesta era -decían- una auténtica desgubernamentalización de la CCMA.

Sin embargo, el 22 de julio de 2015, en vísperas de las elecciones del 27 de septiembre -plebiscitarias, según las fuerzas políticas y sociales nacionalistas-, cuando ya el Parlamento estaba a punto de disolverse, CDC y ERC-que concurrirían juntas en la candidatura Junts pel Sí- optan por cubrir la vacante dejada por Guitart designando, en segunda votación y gracias a la mayoría absoluta que sumaban, a la periodista Rita Marzoa que acababa de abandonar la junta directiva de la entidad independentista Òmnium Cultural, también integrada en la candidatura de Junts pel Sí. De este modo, gracias a la reforma de 2012, las dos principales fuerzas separatistas se garantizaban el control del consejo de administración de la CCMA por personas afines: Duart - presidente, con voto de calidad-, Llorach y Marzoa. Junto a ellos, tres consejeros de perfil constitucionalista, entre ellos Pemán, designado a propuesta de $\mathrm{CiU}$, pero de tendencia democristiana, el sector que se escinde del partido de Mas justo un mes antes de este precipitado nombramiento.

Inmediatamente después de la designación de Marzoa, el 28 de julio, el consejo de administración de la CCMA, argumentando razones de reorganización empresarial, que fueron ampliamente contestadas, cesó al militante de UDC Félix Riera como director de Catalunya Ràdio, con los votos en contra de Pemán, Vilar y Querol (Fernández Viso y Fernández Alonso, 2019: 167-170).

${ }^{13}$ Si bien cabe matizar que en 2010, tras la dimisión de Albert Sáez, entonces presidente de la CCMA a propuesta de ERC, al no apoyar CiU a Enric Marín, el candidato propuesto por el segundo tripartito para sustituirle, el Ejecutivo catalán impulsó el decreto ley 2/2010, que permitía que fuera suficiente la mayoría absoluta para sustituir a los consejeros de la radiotelevisión pública catalana en caso de vacante y, si fuera el caso del presidente, también para la designación del mismo.

Araucaria. Revista Iberoamericana de Filosofí, Política, Humanidades y Relaciones Internacionales, año $23, \mathrm{n}^{\circ} 47$. Segundo cuatrimestre de 2021. Pp. 294-314. ISSN 1575-6823 e-ISSN 2340-2199 https://dx.doi.org/10.12795/araucaria.2021.i47.14 
Al escribir estas líneas, ya en 2021, el consejo de administración está integrado por solo cuatro de aquellos miembros, todos con los cargos caducados salvo Marzoa, por cuanto los mandatos son de seis años. Han dimitido el consejero Vilar y el presidente Duart, este último en mayo de 2018 para incorporarse al Gobierno de Torra, como número dos del Departamento de Interior. Por tanto, la CCMA funciona con solo cuatro miembros, tres de ellos con los cargos caducados, incluida la presidenta en funciones, Llorach, que no ha sido designada por el Parlamento, tal como establece la ley.

En estos años, la labor del referido consejo de administración ha sido muy criticada, sobre todo por atender a los acuerdos entre las dos grandes fuerzas políticas separatistas a la hora de designar a los cargos clave de los medios públicos catalanes. Así, coincidiendo con el mandato de Junts pel Sí (20162017), el PDeCAT -heredero de CDC- propuso al director de Televisió de Catalunya $(\mathrm{TVC})^{14} \mathrm{y}$ al jefe de informativos de Catalunya Ràdio, mientras que ERC propuso al director de Catalunya Ràdio y al jefe de informativos de TVC. Estas prácticas fueron denunciadas por el Sindicato de Periodistas de Cataluña ante el Consejo de Europa en febrero de $2016^{15}$.

De todos estos nombramientos resultó especialmente cuestionado el del aún director de TVC Vicent Sanchis, reprobado en abril de 2017, en una decisión sin precedentes, por el Parlamento de Cataluña. Los diputados de la CUP se desmarcaron de Junts pel Sí, único grupo parlamentario que apoyó el nombramiento. También criticaron abiertamente esta decisión el Comité de Empresa y el Consejo Profesional de TVC, que emitieron un comunicado conjunto en el que afirmaban que "la designación del nuevo director se mantiene dentro de los acuerdos de los partidos del gobierno para repartirse los cargos de la CCMA que permite a la antigua CDC controlar la dirección del Consejo de Administración y de TVC"16.

Al escribir estas líneas numerosos altos cargos de la CCMA, entre ellos la presidenta en funciones y los directores de TVC y Catalunya Ràdio, están procesados por la emisión de publicidad institucional del referendo ilegal del 1-O, que había sido prohibida por el Tribunal Constitucional ${ }^{17}$.

\subsubsection{Evidencias de apoyo al procés}

Con unos cargos de perfil marcadamente separatista -por ejemplo, el jefe de informativos de TVC, David Bassa, llegó a prestar su imagen para la

14 TVC emite el canal generalista TV3, líder de audiencia en Cataluña, y diversos canales temáticos que han ido variando durante los años que contemplamos en este artículo.

15 https://www.sindicatperiodistes.cat/es/content/el-spc-denuncia-los-nombramientos-en-la-ccmaal-consejo-de-europa

${ }^{16}$ http://www.comitetv3.cat/2017/03/volen-tvc-sota-control.html

17 https://www.elconfidencial.com/espana/2019-04-09/procesada-la-cupula-de-tv3-y-cargos-delgovern-por-los-preparativos-del-1-o 1931758/

Araucaria. Revista Iberoamericana de Filosofia, Política, Humanidades y Relaciones Internacionales, año $23, \mathrm{n}^{\circ} 47$. Segundo cuatrimestre de 2021. Pp. 294-314. ISSN 1575-6823 e-ISSN 2340-2199 https://dx.doi.org/10.12795/araucaria.2021.i47.14 
campaña publicitaria "Un millón de firmas para la autodeterminación", lanzada por la International Commission of European Citizens en $2013^{18}$-, han sido frecuentes las críticas a los medios públicos catalanes en el contexto del procés. Señalamos algunas muestras recientes, que han sido seleccionadas porque tienen una relevancia que va más allá de hechos puntuales ${ }^{19}$.

Así, durante varias semanas, antes y después del referendo ilegal del 1 de octubre de 2017, los trabajadores de TVC colgaron en uno de los edificios de la sede de esta empresa pública dos enormes pancartas con la propaganda de la entidad independentista Òmnium Cultural: en una se podía leer la palabra Democràcia y en otra se observaban varios rostros con la boca tachada, simbolizando una supuesta falta de libertad de expresión. En los estudios de la televisión pública catalana también se desplegaron carteles con frases como "votar no es delito"20. La dirección entendió que las pancartas y los carteles quedaban amparados precisamente por la "libertad de expresión" y no ordenó retirarlos.

En relación con los contenidos difundidos por los medios públicos catalanes tras la declaración unilateral de independencia, el Tribunal Supremo ratificaba en marzo de 2020 cuatro acuerdos de la Junta Electoral Central, según los cuales TVC y Catalunya Ràdio vulneraron los principios de neutralidad informativa y pluralismo político durante la campaña electoral que precedió a los comicios autonómicos de diciembre de $2017^{21}$. Y de nuevo el alto tribunal dictaba, en febrero de 2021, una segunda sentencia en el mismo sentido, esta vez por las emisiones realizadas por la televisión pública catalana durante la campaña de las elecciones generales de marzo de $2019^{22}$.

En esta línea, los responsables de informativos de los medios de la CCMA han defendido que, en el propio relato informativo -el elaborado y leído por los redactores-, se utilicen con normalidad conceptos muy reiterados en el discurso separatista, como son "presos políticos", para referirse a los líderes políticos y sociales condenados por sedición tras haber tratado de derogar el orden constitucional en Cataluña; y "exiliados", para referirse a los huidos de la justicia española en Bélgica, Suiza y Escocia ${ }^{23}$. Todo ello en el marco, como apunta el periodista Lluís Bassets (2018: 180), de una narrativa "fuertemente depresiva y victimizadora".

\footnotetext{
${ }^{18}$ Aquí se puede ver el vídeo: https://www.youtube.com/watch?v=jOndCBkRd3k

${ }_{19}$ Si bien cabe mencionar que Sergio Fidalgo (2018), presidente el Grupo de Periodistas Pi i Margall, ha realizado una compilación de 50 hechos puntuales realmente llamativos.

${ }^{20}$ Aquí se recogen fotos del mencionado edificio: https://vertele.eldiario.es/noticias/Pancartasfavor-referendum-sede-TV3 0 1943205695.html

${ }^{21}$ https://www.elmundo.es/espana/2020/03/06/5e624b24fc6c83246d8b460a.html

22 https://cronicaglobal.elespanol.com/politica/supremo-tv3-neutralidad-informativa_450942 102. $\underline{\mathrm{html}}$

${ }^{23}$ https://comunicacio21.cat/opinio/per-que-parlem-dexili-i-de-presos-politics/
} 
Aspectos especialmente denunciados desde sectores constitucionalistas han sido el perfil de invitados y tertulianos, así como los enfoques de los documentales. Con respecto a la primera cuestión, en 2018, tras la petición de un diputado de Ciudadanos, la Presidenta en funciones de la CCMA facilitó en el Parlamento un listado de los invitados al programa de análisis político Més 324, emitido por TVC de lunes a viernes. Al analizar este listado, correspondiente a tres meses, se observa una proporción de uno a cuatro entre los invitados de perfil constitucionalista y los de tendencia nacionalista ${ }^{24}$.

Asimismo, en los informes sobre la observancia del pluralismo político en la televisión y en la radio que elabora regularmente el Consejo Audiovisual de Cataluña (CAC) se aprecia que el tiempo de palabra de las entidades independentistas es abrumadoramente superior. Por ejemplo, en el informe correspondiente al período mayo-diciembre de 2019 vemos que TV3 dedicó a las entidades constitucionalistas solo el 8,1\% del tiempo de palabra y Catalunya Ràdio, el 6,4\%. En este último caso resulta realmente sorprendente que, por ejemplo, disponga de más tiempo la entidad Madrileños por el Derecho a Decidir (1,3\%) que Impulso Ciudadano ( $0 \%$ ), siendo esta última la asociación que logró en septiembre de 2019 la retirada cautelar de la pancarta de apoyo a los presos independentistas del Palau de la Generalitat ${ }^{25}$. Por su parte, Òmnium Cultural copó el 39,5\% del tiempo en TV3 y el 36,2 en Catalunya Ràdio. Se trata de cifras muy similares a las correspondientes al periodo inmediatamente anterior. Así, entre enero y abril del mismo año 2019 el tiempo de palabra en TV3 de las entidades constitucionalistas -en este caso solo Societat Civil Catalana- se redujo al 3,4\%. Y en Catalunya Ràdio, al 2,1\%, frente al 3,1\% de Obra Cultural Balear y el 2,8\% de Madrileños por el Derecho a Decidir ${ }^{26}$. Òmnium Cultural absorbió en este caso el 45,3\% del tiempo de TV3 y el 47,4\% de Catalunya Ràdio.

Un hecho muy comentado fue la renuncia, en octubre de 2017, de dos conocidos periodistas, Joan López Alegre e Ignacio Martín Blanco, a seguir colaborando como tertulianos en los medios públicos catalanes. En un durísimo artículo publicado en El País afirmaban que "preferimos renunciar a nuestros emolumentos que seguir aguantando el desgaste emocional que supone participar en ese circo del odio a España y la carga moral de pensar que nuestra presencia lo legitima" ${ }^{27}$.

Con respecto a los documentales, en diciembre de 2019, en otra comparecencia parlamentaria, la presidenta en funciones de la CCMA afirmó que no existen producciones de este tipo en el mercado que recojan las tesis

\footnotetext{
${ }^{24} \mathrm{https}$ ://cronicaglobal.elespanol.com/politica/tertulianos-indepes-cuadruplicanconstitucionalistas-tv3 210636 102.html

${ }^{25} \mathrm{https://www.cac.cat/sites/default/files/2020-05/Acord} 432020$ ca.pdf.pdf (pág. 27)

${ }^{26} \mathrm{https} / / / \mathrm{www} . c a c . c a t /$ sites/default/files/2020-01/Acord_3_2020_ca.pdf (pág. 28)

27 https://elpais.com/elpais/2017/10/09/opinion/1507565383 489219.html
} 
constitucionalistas $^{28}$, reconociendo así, que ciertamente no se emiten, tal como han reivindicado en numerosas ocasiones entidades contrarias a la independencia como Societat Civil Catalana ${ }^{29}$ o la Asamblea por una Escuela Bilingüe $\mathrm{e}^{30}$.

Así las cosas, una encuesta publicada por GESOP en 2017 constataba que el $65 \%$ de los catalanes considera que TVC y Catalunya Ràdio se muestran favorables a la independencia mientras que solo un $22 \%$ cree que son neutrales ${ }^{31}$.

\subsection{Licencias de emisión a grupos de línea editorial nacionalista}

Si bien Cataluña es la única comunidad autónoma que cuenta con un múltiplex completo de TDT de cobertura autonómica destinado al sector privado -adjudicado íntegro al Grupo Godó en 2003-, así como con una cuarentena de televisiones locales comerciales, durante los años del procés únicamente se abrió un proceso de concesión de licencias radiofónicas, en 2014: se sacaron a concurso público 22 frecuencias correspondientes al Plan Técnico Nacional de Frecuencia Modulada (FM) aprobado en 2006 (Real Decreto 964/2006) ${ }^{32}$.

Los principales beneficiarios de este concurso, resuelto por el CAC, fueron el Grupo Godó, con nueve, y el Grupo Flaix, con seis. Godó es el propietario de $R A C 1$, una cadena radiofónica de línea editorial claramente independentista y líder de audiencia en Cataluña, mientras que Flaix era entonces propiedad de Miquel Calçada, quien un año después sería candidato de Junts pel Sí en las elecciones autonómicas (Fernández Alonso y Espín, 2015: 29).

Prueba de la relevancia que las fuerzas políticas nacionalistas conceden a los medios -en este caso, audiovisuales- es que, según consta en un informe de la Guardia Civil de junio de 2018, el Gobierno de Puigdemont tenía preparado desde 2016, con logo de la Generalitat incluido, un modelo de carta que, tras la declaración de independencia, pensaba dirigir a los responsables de los grupos de comunicación con licencia para emitir canales de TDT en todo el territorio español para informarles de que, aunque se mantendrían sus emisiones de manera provisional, próximamente les informarían sobre cómo se llevaría a cabo el proceso para otorgar de manera definitiva las pertinentes licencias en el marco jurídico de la Cataluña independiente.

\footnotetext{
${ }^{28} \mathrm{https}$ //cronicaglobal.elespanol.com/politica/tv3-justifica-sesgo-indepe-unicos-contenidoscalidad $297515 \quad 102 . \mathrm{html}$

29 https://www.lavanguardia.com/politica/20150105/54422371404/scc-reclama-que-tv3-emitatambien-documentales-contrarios-a-la-independencia.html

${ }^{30} \mathrm{https} / /$ www.aebcatalunya.org/es/comunicados/143-la-aeb-pide-al-cac-que-tv3-elabore-otro-30minuts-con-las-voces-silenciadas-en-el-reportaje- $\%$ E2 $\% 80 \% 9$ Ceducar-sota-sospita $\%$ E2 $\% 80 \% 9 \mathrm{D}$

${ }^{31} \mathrm{https}$ :/www.eltriangle.eu/es/actualidad/media/el-65-de-los-catalanes-cree-que-tv3-esindependentista 44759 102.html

32 Estas frecuencias habían sido adjudicadas inicialmente a COMRàdio, una cadena pública dependiente del gobierno provincial de Barcelona que cesó sus emisiones en 2012.
}

Araucaria. Revista Iberoamericana de Filosofía, Política, Humanidades y Relaciones Internacionales, año $23, \mathrm{n}^{\circ} 47$. Segundo cuatrimestre de 2021. Pp. 294-314. ISSN 1575-6823 e-ISSN 2340-2199 https://dx.doi.org/10.12795/araucaria.2021.i47.14 
Junto a esta carta se encontraron otras dirigidas, por ejemplo, al Gobierno español, en estos términos: "Cataluña dispone ahora de plenas competencias en el ámbito de las telecomunicaciones y los servicios de comunicación audiovisual, y quería expresarle nuestra más sincera voluntad de colaboración entre los dos países en todo aquello que hace referencia a este marco competencial".

La Generalitat también tenía preparadas misivas para organismos internacionales como la Unión Internacional de Telecomunicaciones (UIT), el Grupo de Reguladores Europeos de Servicios de Medios Audiovisuales (ERGA) o la Unión Europea de Radiodifusión (UER), con el ánimo de ocupar un asiento en estas organizaciones ${ }^{33}$.

\subsection{Clientelismo en la financiación del sector mediático privado}

Existen diversas fórmulas de transferencia de dinero desde las administraciones públicas a los medios. Una de ellas son las subvenciones. En Cataluña tradicionalmente se han otorgado dos modalidades: las denominadas ayudas estructurales -que se conceden fundamentalmente con criterios de difusión, únicamente a los medios en catalán- y las ayudas a proyectos, normalmente articuladas en torno a la idea de la financiación de propuestas que contribuyan a fortalecer el denominado espai català de comunicació, lo que otorga un enorme margen de discrecionalidad al gobierno que las concede.

Sin embargo, en 2013, en el contexto de los recortes derivados de la crisis financiera, estas últimas fueron suprimidas, manteniéndose las primeras hasta el momento de cerrar este texto. En los años álgidos del procés estas ayudas superaron ligeramente los 6,5 millones de euros, reservándose una cantidad en torno a los 700/800.000 euros para organizaciones profesionales del sector (Fernández Alonso y Espín, 2019: 51).

Otra fórmula, muy opaca, de transferencia de dinero de las administraciones a los medios son las compras de ejemplares en bloque. Disponemos de los datos correspondientes a 2015, gracias a una pregunta parlamentaria del grupo Catalunya Sí que es Pot. La Generalitat invirtió ese año 940.000 euros para este fin, siendo los grandes beneficiarios los cuatro diarios catalanes de alcance autonómico: La Vanguardia (225.000), El Punt Avui (125.000), El Periódico (66.337) y Ara (49.588) (Fernández Alonso y Espín, 2017: 48-49). De estos, los que tienen una línea abiertamente afín a la causa independentista son el segundo y el cuarto, que habían recibido en 2010, de manera totalmente discrecional, cuantiosas cantidades: El Punt Avui, 1,5 millones de euros por la fusión de las dos cabeceras -El Punt y Avui- y Ara, 990.000 euros, por su lanzamiento ${ }^{34}$.

\footnotetext{
https://www.elconfidencial.com/espana/2018-06-25/puigdemont-independencia-licenciasradio-television-mediaset-atresmedia-cope-ser-rtve 1582863/

${ }^{34}$ Diari Oficial de la Generalitat de Cataluña, 9 de mayo de 2011, pp. 26.377 y 26.378.
} 
En tercer lugar, desde 2016 la Generalitat publica en su Portal de Transparencia las cifras relativas a los ingresos que perciben las empresas de medios en concepto de publicidad institucional, sin duda la principal fórmula de transferencia de fondos públicos a los negocios periodísticos ${ }^{35}$. Así, en el periodo analizado, el presupuesto por este concepto se eleva de 15,8 millones de euros en 2012 a 32,4 en $2018^{36}$-el más cuantioso de los gobiernos autonómicos, según datos facilitados a la autora por la consultora Arce Media-, lo que explicaría las evidentes tensiones entre los dos grandes partidos independentistas por gestionar esta materia, tal como han documentado los medios ${ }^{37}$.

A título orientativo, si cogemos las cifras de 2017, se pueden constatar hechos tan llamativos como que el diario en papel que más ingresa es El Punt Avui (2.525.013 euros), con una cifra de difusión de 21.692 ejemplares. Y frente a él, por ejemplo, El Mundo, un diario de alcance español -con una edición especial para Cataluña-, muy crítico con el nacionalismo, percibe 7.159 euros vendiendo 5.205 ejemplares en esta comunidad. Es decir, el diario independentista multiplica por 4,16 la difusión del constitucionalista y por 352,7 los ingresos provenientes de la administración autonómica catalana en concepto de publicidad institucional.

También se observa, por indicar un segundo ejemplo, que ese mismo año 2017 el diario digital catalán de referencia del constitucionalismo, Crónica Global, no recibió ni un solo euro en concepto de publicidad institucional mientras que el más visitado por los separatistas, El Nacional, percibió 427.473.

Y algo similar sucede en el ámbito radiofónico. Sorprenden los 19.938 euros que ingresa la COPE (195.000 oyentes en 2017) frente a los 1.051.288 transferidos a $R A C 1$ ( 878.000 oyentes). La cadena de Godó, de línea editorial claramente independentista, cuenta con una audiencia 4,5 veces superior a la de la emisora de la Conferencia Episcopal y unos ingresos por campañas institucionales 52,7 veces superiores. Del mismo modo, sorprenden los 137.619 euros que ingresa Cadena 40 (300.000 oyentes) frente a los 255.025 de $R A C 105$ $\left(238.000\right.$ oyentes $\left.^{38}\right)$. En este caso, nos encontramos con que la radio temática de Godó casi duplica en ingresos por publicidad pública a la de PRISA, pese a que su audiencia es inferior en 62.000 oyentes.

En relación con este tema, el 29 de junio de 2017, en vísperas del referéndum ilegal del 1 de octubre, el Parlamento de Cataluña, con los votos de los

${ }^{35} \mathrm{http}: / /$ governobert.gencat.cat/es/transparencia/Gestio-serveis-publics/memoria-sobre-publicitatinstitucional/

${ }^{36}$ En el momento de escribir estas líneas la última memoria publicada de la Comisión Asesora sobre la Publicidad Institucional (CAPI) de la Generalitat de Cataluña es la correspondiente a 2018.

${ }^{37} \mathrm{https}: / / w w w . e l c o n f i d e n c i a l . c o m / e s p a n a / 2018-06-25 /$ artadi-medios-publicidad-difusioncomunicacion-independencia 1583489/

${ }^{38}$ Los datos de difusión de prensa y de audiencia de radio que se recogen en este epígrafe están tomados del Informe de la comunicación a Catalunya 2017-2018: https://incom.uab.cat/informe/ edicion.html?id=17

Araucaria. Revista Iberoamericana de Filosofía, Política, Humanidades y Relaciones Internacionales, año $23, \mathrm{n}^{\circ} 47$. Segundo cuatrimestre de 2021. Pp. 294-314. ISSN 1575-6823 e-ISSN 2340-2199 https://dx.doi.org/10.12795/araucaria.2021.i47.14 
diputados independentistas - Junts pel Sí y la CUP-, aprobó una moción según la cual para que la Generalitat contratase espacios de publicidad institucional con un medio, este debía comprometerse a difundir cualquier campaña del Gobierno, incluidas las relativas al mencionado referendo, prohibido, como hemos indicado, por el Tribunal Constitucional (Fernández Alonso y Espín, 2019: 51).

\subsection{Presión y seducción a la prensa extranjera}

Finalmente, cabe apuntar que, en este periodo, los ejecutivos catalanes no solo trataron de incidir -como hemos demostrado- en el discurso de los medios catalanes sino que existen claros indicadores de las presiones que ejercieron sobre profesionales de la información de otros países, especialmente en los momentos álgidos del procés. Muestra de ello, el informe difundido por Reporteros sin Fronteras en octubre de 2017. En la nota de prensa que lo acompaña, se afirma que "ante denuncias de varios periodistas, catalanes, españoles y extranjeros sobre linchamientos en las redes sociales aparentemente instigados y/o secundados en entornos de poder en Cataluña, así como sobre presiones reiteradas por parte de determinados responsables de Comunicación del Gobierno autónomo catalán", esta ONG recabó evidencias que le permitieron concluir que "las quejas relativas a 'ciberacoso' y 'presiones del poder' fueron secundadas de forma casi unánime, con testimonios y pruebas" ${ }^{\text {" }}$.

Un testimonio en esta línea, que no se recoge en este informe, es el de la corresponsal francesa Sandrine Morel, quien relata cómo, en una ocasión, "un responsable de prensa de la Generalitat, con el que mantenía una relación profesional de confianza (...) me soltó mientras tomábamos un café: 'Si compramos dos páginas de publicidad en Le Monde, tus jefes te dirán qué debes escribir..."'. Explica Morel que, al observar su indignación, "se disculpó añadiendo: 'Bueno, así funcionan las cosas aquí'” (Morel, 2018: 17).

El también periodista Juan Pablo Cardenal (2020: 33-44) -tras subrayar la llamativa renuncia del Gobierno de España a librar la batalla del relato frente al separatismo catalán- destaca, junto a diversas muestras de las referidas presiones denunciadas por Reporteros sin Fronteras, la creación en 2012, por parte del Ejecutivo de la Generalitat, del Programa internacional de comunicación y relaciones públicas Eugeni Xammar, orientado a "actuar como ventanilla única para la prensa extranjera", respondiendo con agilidad a todas las consultas, peticiones de entrevistas o fuentes, traduciendo notas de prensa a varios idiomas, preparando argumentarios u organizando visitas de periodistas. Explica Cardenal que este programa tuvo un importante impacto en la cobertura

39 https://www.rsf-es.org/informe-rsf-respectpresscat-0112-reporteros-sin-fronteras-pide-respetoal-libre-ejercicio-del-periodismo-en-cataluna/

Araucaria. Revista Iberoamericana de Filosofía, Política, Humanidades y Relaciones Internacionales, año $23, \mathrm{n}^{\circ} 47$. Segundo cuatrimestre de 2021. Pp. 294-314. ISSN 1575-6823 e-ISSN 2340-2199 https://dx.doi.org/10.12795/araucaria.2021.i47.14 
periodística internacional, especialmente la de los medios anglosajones, que pasaron a ver con mucha más simpatía la causa nacionalista.

\section{Balance y ausencia de contrapesos}

Desde la configuración del Estado autonómico en España, en los años de transición a la democracia, los sucesivos gobiernos de la Generalitat han apostado con fuerza por implementar políticas de comunicación orientadas a la articulación de un sistema mediático propio que, a su vez, contribuya a la denominada construcción nacional de Cataluña.

Para lograrlo han actuado tanto en el ámbito de los medios públicos como privados. En el primero, impulsando una corporación audiovisual que ha resultado muy exitosa en términos de audiencia. En el segundo, adjudicando licencias de TDT autonómica y local y de radio en FM a empresas autóctonas -está pendiente un estudio de los criterios de los diferentes concursos, si bien no es factible el acceso a los expedientes- $\mathrm{y}$ otorgando a estas mismas empresas abundantes subvenciones y sobre todo ingresos vinculados a la difusión de campañas de publicidad institucional.

Cataluña es la comunidad autónoma que más dinero ha destinado a sus medios públicos regionales y también a la financiación de los privados. Asimismo ha logrado, en una permanente tensión competencial con el Estado, disponer de muchas frecuencias de radio y televisión terrestre. Por ejemplo, cuenta con el doble de espectro que todas las demás comunidades para emisiones de TDT de cobertura autonómica.

Se observa, en definitiva, un intervencionismo gubernamental especialmente marcado en relación con otras comunidades autónomas españolas por cuanto a los rasgos característicos de los sistemas mediáticos pluralistas polarizados se suma la referida estrategia nacionalista.

Con el giro independentista del nacionalismo catalán a partir de 2012 ese intervencionismo se intensifica de forma notable. Muestra de ello son, por ejemplo, el pacto entre las fuerzas secesionistas gobernantes -denunciado en diferentes ámbitos y nunca desmentido por los implicados- para repartirse los principales cargos de la radio y televisión pública, condicionando para ello el voto de los miembros del Consejo de Administración de la CCMA, que son quienes realmente los eligen; o la evidente presión a estos mismos consejeros y demás cargos de la corporación audiovisual pública catalana para la difusión de la publicidad institucional del referendo ilegal, explícitamente prohibida por el Tribunal Constitucional y ahora investigada por el Juzgado de Instrucción $\mathrm{n}^{\mathrm{o}} 13$ de Barcelona. Es realmente llamativo que en el relato informativo de los medios públicos catalanes se hable -copiando claramente el lenguaje de las 
fuerzas políticas y sociales nacionalistas- de "presos políticos" y "exiliados" para referirse a los líderes independentistas encarcelados tras un juicio realizado con todas las garantías y a los huidos al extranjero para evitar ser juzgados por los hechos acaecidos en Cataluña en otoño de 2017.

Otras evidencias llamativas de la intensificación del intervencionismo del Ejecutivo catalán, en este caso en el sector mediático privado, son el creciente incremento del presupuesto -si bien es cierto que la crisis había implicado un recorte enorme- destinado a unas campañas de publicidad institucional siempre planificadas con criterios de afinidad política; o la aprobación de una moción parlamentaria que apuntaba que para que una empresa pudiera resultar beneficiaria de una campaña de publicidad pública debería comprometerse a insertar los anuncios del referendo ilegal del 1-O. Todo ello sin olvidar las cartas que había preparado el Gobierno de Puigdemont ya en 2016 para advertir a las empresas titulares de licencias de TDT de cobertura estatal de que las perderían en el contexto de la Cataluña independiente, ni los agasajos y presiones a la prensa extranjera que hemos descrito.

A la vez, los mecanismos de control existentes, como el regulador supuestamente independiente, el Consejo del Audiovisual de Cataluña (CAC), se han mostrado manifiestamente ineficientes, al dejar, por ejemplo, sistemáticamente sin sanción las quejas relativas a cuestiones de pluralismo en los medios públicos o las emisiones claramente irregulares de medios independentistas como El Punt Avui TV ${ }^{40}$ (Fernández Alonso, 2017).

Los consejeros del CAC propuestos por fuerzas políticas constitucionalistas -siempre en minoría por el voto de calidad de presidente- han llegado a denunciar la contratación de una empresa para realizar un seguimiento de sus redes sociales ${ }^{41}$. Desde 2020, este regulador funciona con solo cuatro de sus seis consejeros que, además, tienen los cargos caducados. Es muy significativo que uno de los ex consejeros, Salvador Alsius, ya jubilado, y que nunca realizó ningún voto de condena ante las quejas relativas a los contenidos de los medios públicos, afirmara en una entrevista, en junio de 2020, que "es una evidencia" que muchos de los programas de TV3 “están sesgados por la manera de hacer de sus tertulianos" $"$.

40 Este canal de televisión local emitía la misma programación en diferentes demarcaciones, vulnerando así la normativa que le obligaba a elaborar contenidos específicos para cada territorio en el que había obtenido una licencia.

${ }^{41} \mathrm{https}$ ://www.vozpopuli.com/economia-y-finanzas/empresas/constitucionalistas-CACdenuncian-coacciones-expresar-opinion-proces_0 1134188045.html A la vez, el Juzgado de lo Contencioso Administrativo $n^{\circ} 11$ de Barcelona anuló, en junio de 2020, un acuerdo del CAC debido a que los consejeros propuestos por los partidos independentistas forzaron, mediante votación, la abstención de un consejero propuesto por el PPC, contraviniendo así las causas de abstención que fija la normativa administrativa: https://www.abc.es/espana/catalunya/politica/abci-justicia-anulaacuerdo-exculpo-terribas-seguimiento-policias-desde-radio-202006291412 noticia.html

42 https:/www.naciodigital.cat/noticia/203671/salvador/alsius/aixecat/muralla/infranquejable/ part/pais/ni/conya/miraria/tv3

Araucaria. Revista Iberoamericana de Filosofia, Política, Humanidades y Relaciones Internacionales, año $23, \mathrm{n}^{\circ} 47$. Segundo cuatrimestre de 2021. Pp. 294-314. ISSN 1575-6823 e-ISSN 2340-2199 https://dx.doi.org/10.12795/araucaria.2021.i47.14 
A la ineficacia del CAC cabe añadir la imposibilidad de recurrir al regulador español -la Comisión Nacional de los Mercados y de la Competencia (CNMC) - cuando se observa algún comportamiento irregular en operadores que no superan el ámbito de cobertura autonómico. Y, sobre todo, la espiral de silencio existente en los ámbitos profesional y académico donde las voces críticas son habas contadas. No en vano, y por más que esto atenta contra el derecho fundamental a la libertad ideológica de sus asociados ${ }^{43}$, el Colegio de Periodistas de Cataluña ya se adhirió en 2012 a una resolución del Parlamento de Cataluña a favor del denominado "derecho a decidir" 4 , mientras que los claustros de todas las universidades públicas catalanas aprobaron un manifiesto único en contra de la sentencia del Tribunal Supremo que condenó en octubre de 2019 a diversos líderes políticos y sociales separatistas por diversos delitos, entre ellos, la sedición ${ }^{45}$.

\section{Bibliografía}

Bassets, Lluís (2018): “Los maestros narradores del independentismo: medios, propaganda, redes". En Coll, Joaquim et al. (ed.): Anatomía del procés. Claves de la mayor crisis de la democracia española. Barcelona: Debate, pp. 159-180.

Cardenal, Juan Pablo (2020): La Telaraña. La trama exterior del procés. Barcelona: Ariel. Casado, Miguel Ángel et al. (2017): "Medios públicos autonómicos: merma en la financiación, gobierno parlamentario y externalización creciente de la gestión". En Fernández Alonso, Isabel (ed.): Austeridad y clientelismo. Política audiovisual en España en el contexto mediterráneo y de la crisis financiera. Barcelona: Gedisa, pp. 197-218.

Civil, Marta at al. (ed.) (2013): Informe de la comunicació a Catalunya 2011-2012. Barcelona: Generalitat de Catalunya.

Coll, Joquim (2018): "El procés: de la ilusión a la insurrección frustrada". En Coll, Joaquim et al. (ed.): Anatomía del procés. Claves de la mayor crisis de la democracia española. Barcelona: Debate, pp. 21-46.

Fernández Alonso, Isabel (2017): "La independencia de los organismos reguladores y de control. El caso del Consell de l'Audiovisual de Catalunya: Análisis de las actuaciones más controvertidas en el contexto del debate secesionista (2012-2015)". En Boix, Andrés et al. (coord.): La regulación de los contenidos audiovisuales. Cizur: Aranzadi, pp. 367-384.

Fernández Alonso, Isabel y Espín, Marc (2015): "Les polítiques de comunicació". En Civil, Marta et al. (ed.): Informe de la comunicació a Catalunya 2013-2014. Barcelona: Generalitat de Catalunya, pp.21-32.

\footnotetext{
${ }^{43}$ Así lo ha establecido el Tribunal Superior de Justicia de Cataluña en relación con un pronunciamiento similar del Colegio de Abogados de Barcelona: https://www.europapress.es/nacional/ noticia-tsjc-obliga-colegio-abogados-barcelona-dejar-pacto-derecho-decidir-20161216190617.html

${ }^{44} \mathrm{https} / /$ comunicacio21.cat/noticies/el-col-legi-de-periodistes-a-favor-del-dret-a-decidir/

45 https://www.elnacional.cat/es/politica/manifiesto-conjunto-universidades-catalanas-sentenciaproces $433293 \quad 102$.html
}

Araucaria. Revista Iberoamericana de Filosofía, Política, Humanidades y Relaciones Internacionales, año $23, \mathrm{n}^{\circ} 47$. Segundo cuatrimestre de 2021. Pp. 294-314. ISSN 1575-6823 e-ISSN 2340-2199 https://dx.doi.org/10.12795/araucaria.2021.i47.14 
Fernández Alonso, Isabel y Espín, Marc (2017): "Les polítiques de comunicación". En Civil, Marta et al (ed.): Informe de la comunicació a Catalunya 2015-2016. Barcelona: Generalitat de Catalunya, pp. 37-49.

Fernández Alonso, Isabel y Espín, Marc (2019): "Les polítiques de comunicación”. En Civil, Marta y López, Bernat (ed.): Informe de la comunicació a Catalunya 20172018. Barcelona: Generalitat de Catalunya, pp. 39-52.

Fernández Viso, Ana y Fernández Alonso, Isabel (2019): "Political Interference in the Spanish and Catalan Public Service Media: Attemps to Reform and Resistence to Change (2006-2017)". En Polonska, Eva y Beckett, Charlie (ed.): Public Service Broadcasting and Media Systems in Troubled European Democracies. Londres: Palgrave Macmillan, pp. 155-176.

Fidalgo, Sergio (2018): 50 "hazañas" de TV3. Barcelona: Ediciones Hildy.

Gifreu, Josep (1986): El debate internacional de la comunicación. Barcelona: Ariel.

Gifreu, Josep (1983): Sistema i polítiques de la comunicació a Catalunya. Barcelona: L'Avenç.

Gifreu, Josep y Corominas, Maria (1991): Construir l'espai català de comunicació. Barcelona: Centre d'Investigació de la Comunicació de la Generalitat de Catalunya. Guimerà i Orts, Josep Àngel (2014): Les polítiques de mitjans de comunicació durant els governs de Jordi Pujol: premsa, ràdio i televisió en el procés de reconstrucció nacional de Catalunya. Barcelona: Proa.

Guimerà, Josep Àngel y Fernández Viso, Ana (2014): "National reconstruction and the Media in Catalonia". En Jones, Huw David (ed): The Media in Europe's Small Nations. Newcastle upon Tyne: Cambridge Scholars Publishing, pp. 47-65.

Hallin, Daniel y Mancini, Paolo (2008): Sistemas mediáticos comparados. Barcelona: Hacer.

Miguel, Juan Carlos y Casado, Miguel Ángel (coord.) (2012): Televisiones autonómicas. Evolución y crisis del modelo público de proximidad. Barcelona: Gedisa.

Morel, Sandrine (2018): En el huracán catalán. Una mirada privilegiada al laberinto del procés. Barcelona: Planeta. 